\title{
المعالجة الإخراجية لموضوعة الإرهاب في الفيلم القصير
}

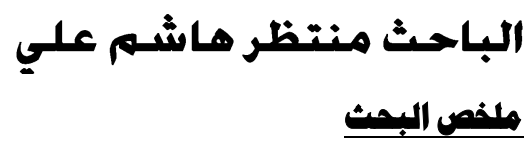

يشكل الإرهاب في الوقت الحاضر مشكلة كبيرة تواجه البلدان بثكل عام وقد تناولت السينما هذا الموضوع بأثكال متعددة ، وفي العراق تحديداً تناول المخرجون هذا الموضوع بثكل واسع وخصوصاً في الفلم القصير إذ لا يخلو أيّ محفل في العراق من هذه الموضوعة ومن هنـا جاء هذا البحث الذي تكون من خمسة فصول تناول الإطار المنهي للبحث وقد شمل على عرض لموضون وضوع مشكلة البحث التي هي (( الكيفيات التي تناول فيها

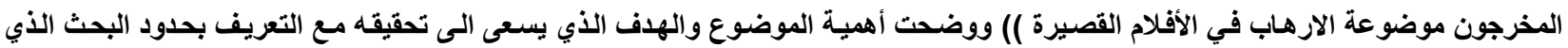

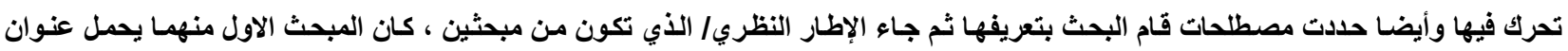
(سمات الفيلم القصير) والمبحث الثاني بعنوان(إثـغالات العناصر السينمائية لموضوعة الإرهـاب) وقد توصل الباحث إلى خمسـة مؤشرات، وأمسا إجراعات البحث، فقد حدد فيه الباحث منهج البحث معتمدا على المنهج الوصفي التحليلي المنسجم مـع طبيعة البحث ومتطلباته ومن ثم اداة البحث وهي المؤشرات التي خرج بها الباحث من بحثه والتي اعتمدها بتحليل عينة أفلامـه ، وأخيراً ختم البحث بالنتائج والتوصيات والمقترحات و قائمـة

المصادر وملخص البحث باللغة الانكليزية.

Summary

At present, terrorism is a big problem facing countries in general. Cinema has dealt with this issue in many ways. In Iraq, the filmmakers dealt with this issue in a large way, especially in the short film. There is no festival in Iraq. Five chapters dealt with the methodological framework of the research and included a presentation on the subject of the research problem, which is ((What is the quality in which the directors dealt with the subject of terrorism in short films), and explained the importance of the subject and the objective that he seeks to achieve with the researcher's definition of the limits of his research, Alba And the second was the title of "The features of the short film" and the second topic entitled "The preoccupations of the cinematic elements of terrorism." The researcher reached five indicators. The research procedures, in which the researcher defined the research methodology based on The analytical descriptive approach for its suitability to the nature of the research and its requirements and then the research tool which are the indicators that emerged from the researcher's research and adopted by analyzing the sample of his films and then came the results, recommendations and proposals and finally the list of sources and summary of the research in English.

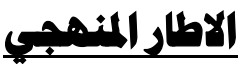

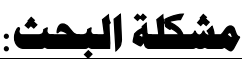

برزت الى الساحة الفنية عموماً والسينمائية خصوصـاً أعمال و أفلام تكافح ظـاهرة الار هـاب وقد عمدت في بحثي هذا ان أتطرق الى الكيفية التي تعامل معها المخرجين في التصدي لتلك الظاهرة عبر الوسيط التعبيري( السينما توغر افي) لما يمثله الار هاب في الوقت الراهن من مشكلة كبيرة تواجه المجتمع وقد برزت هذه الظاهرة بشكل ملفت

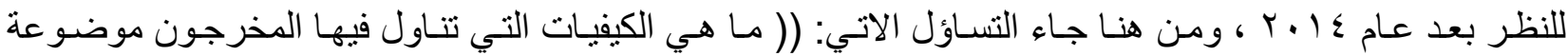
الإر هاب في الأفلام القصبرة)).

(An)

تتجلى اهمية البحث في دراسة اهم المعالجات الاخر اجية التي وظفها المخرج السينمائي في معالجـة الإرهاب في الأفلام القصيرة • وفي تسليط الضوء على ظاهرة الارهاب وكيفية التعامل معها في السينما.

|

يهدف البحث للتعرف على كيفية تحقيق الرؤية الاخر اجية لموضو عة الإرهاب في الافلام القصيرة. 
الحد الموضوعي: الرؤية الإخراجية لموضوعة الارهاب في الافلام القصيرة

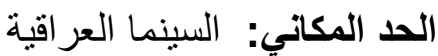

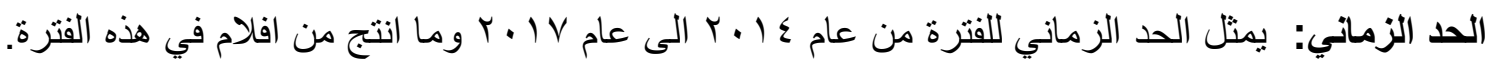

تصديد المصطات

تعريف الفيلم القصير: إن مفردة الفيلم القصير تطلق على "اي فيلم يقل طوله عن ثلاثة آلاف قدم من الفيلم

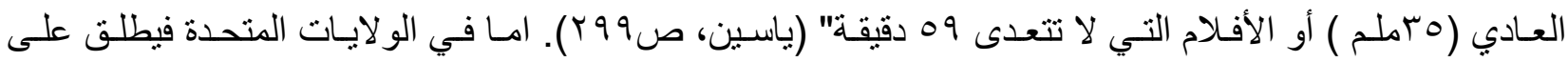

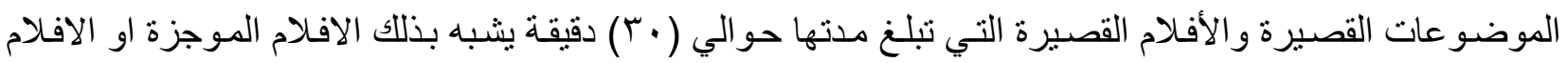

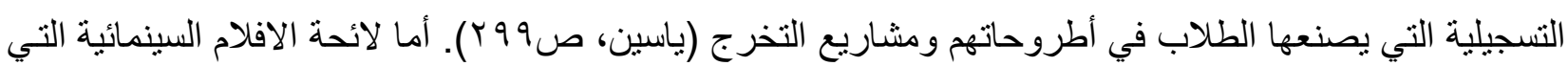

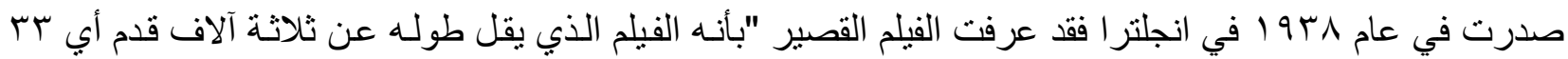
دقيقة ويتضمن الجريدة السينمائية والرسوم المتحركة والأفلام الهزلية والموضو عات القصيرة وعرفهـ نايت بالفلم الثخصي أو المنفرد او نظام مروري خاص في استر اتيجية زمانية وبنية حكائية او حكاية بسيطة تكون فيه الحبكة غير معقدة تعطي لنا لمحة لنخص معين في لحظة معينة ومحورية في حياته ،لحظة تقع عندما يقوم حدث او اختيار

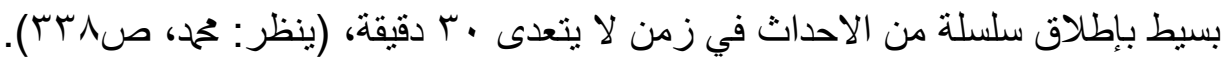

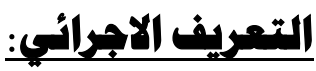

استنادا لهذه التعريفات نستطيع أن نعرف الفيلم القصير بأنه الفيلم الذي يحتوي على مو اضيع محددة ويعرض

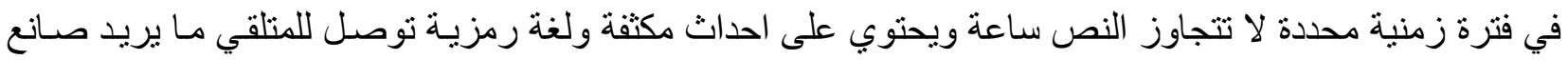

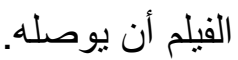

الاطار النظري المبمث الأول: مفهوم الفيلم القصي

بداية عالم السينما ظهر من الفيلم القصير من التجارب الاولى للسينما وتطور شيئاً فثنيئا حتى ظهور الفلم الروائي الطويل (مولد امة ) على يد (اي دبليو غريفث )الذي يعد الانطلاقة الاولى نحو الافلام الروائية الطويلة و"لقد

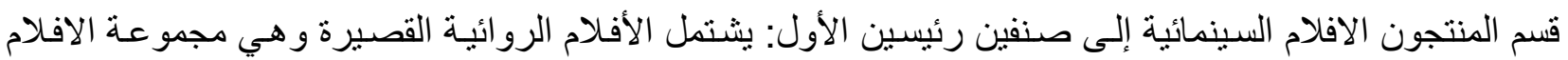

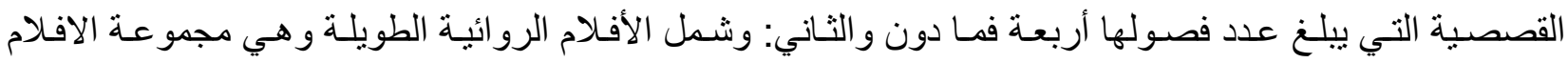

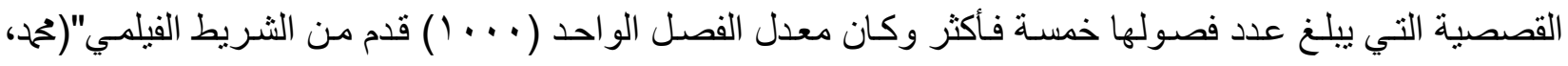

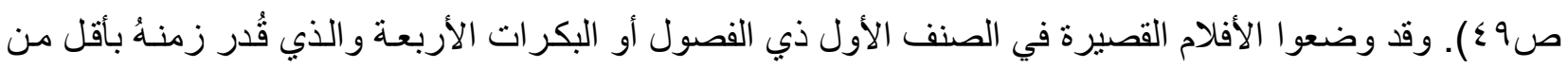

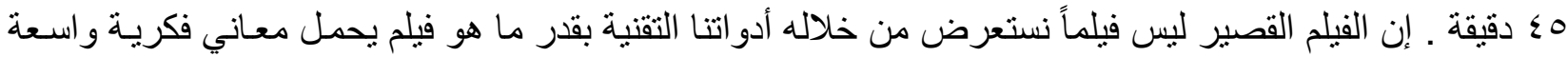
و عميقة توصل من خلالها فكرة ومغزى معين ييقى راسخ في العقل على الرغم من أن المدة التي نشاهد فيها الفيلم قد

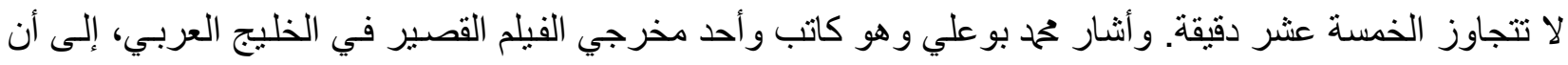
الفيلم القصير فن مختلف تماما عن الفيلم الطويل من حيث البناءو الأسلوب و السرد و الفرق بينهما يعد أكبر اثكالية 
يو اجهها صناع السينما و على وجه الخصوص من لا يتابع الأفلام بشكل مستمر، إن متعة مشـاهدة الفيلم القصير متعـة فريدة من نو عها ومميزة ومختلفة عن سو اها من مشاهدة كافة الأنواع الفيلمية الأخرى فهو شكل خاص ومكثف فقيـه

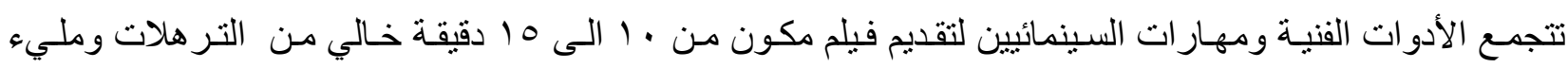

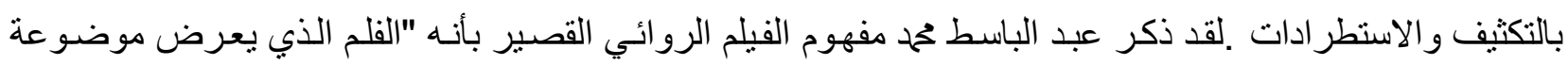

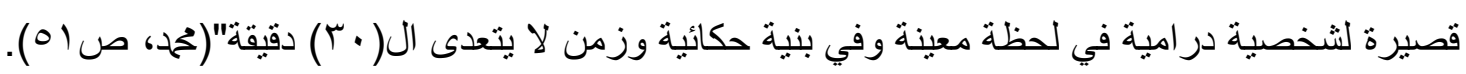

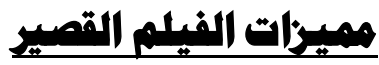

لكل عمل ولكل شكل ولكل انجاز يقوم به الإنسان ميزات تميزه عن غيره وهذه الميزات تتفرد بالعمل نفسـه وبما ان الفيلم القصير هو" ليس مجرد فيلم يحتوي على مشاهد قصيرة أو دقائق قليلة بل هو اتجاه من اتجاهـات السينما و هو فن قائم بذاته يتميز بـالتكثيف و الإيحـاء ؛ لذا فهو يعتمد على الكم الصـوري الضروري للبنـاء الفيلمي فجميع تعريفات الفيلم القصير تتحدث عن التركيز والإيجاز و الاختز ال و التكثيف في الثخصيات و الزمـان و المكان و الأحداث ومن هنا نسنطيع أن نعطي ميزات للفيلم القصير تميزه عن غيره مثل الفيلم الروائي الطويل او الفيلم التسجيلي وهذه وني الميز ات هي:- (nئ

'. الصورة في الفيلم الروائي القصير رمزيـة قابلة للتأويل تمتـاز بـالثراء المعنوي محتملـة العديد من الدلالات

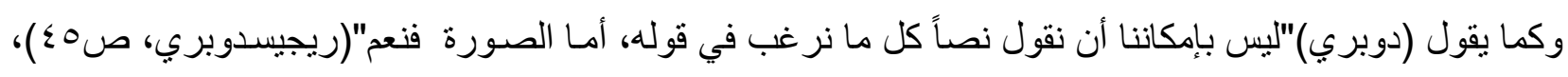
يحتوي الفيلم القصير على عنصر التكثيف فالفلم يجب أن يختصـر شخصياته لأنها يهتم بـإبراز مشكلة معينـة في شخصية معينة أو شخصيات معدودة وتعالج حالة الصر اع فيها.

r. لا يعطي الفيلم القصير مساحة كبيرة لصانع الفيلم للاسترخاء و الترهل في التعبير عن الفكرة، فلكي يخلق لغة

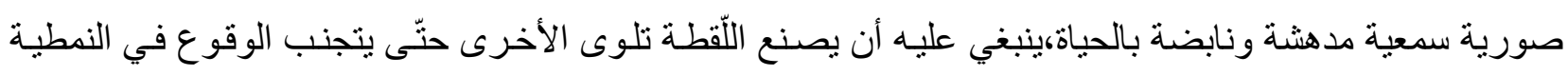

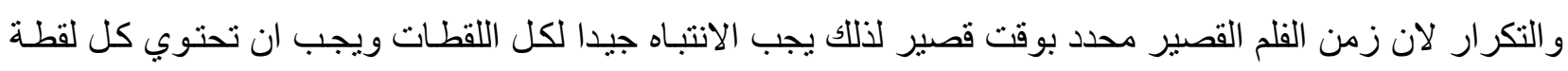
على شيء جديد يدعم اللقطة السابقة وأيضا يدفع القصة إلى الامام.

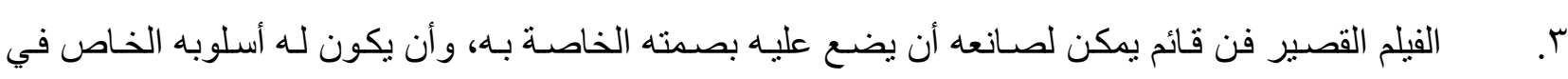
تقديمه للمشاهدين.

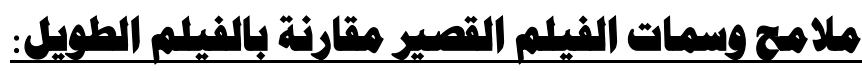

إن الفيلم القصير يمضـي بطريقة أكثر بسـاطة وحريـة من الفيلم الطويل وتكمن البسـاطة في العدد المحدود للثخصيات التي لا تزيد في الأغلب عن ثلاث أو أربع واستخدام الاقتصاد في الاسلوب و التأمل في رسم الثخصية. و هذا ما نر اه في اغلب الأفلام القصيرة حيث تكون القصـة مركزة و لا تحتوي على الثخصبات الكثيرة لأنـه محكوم

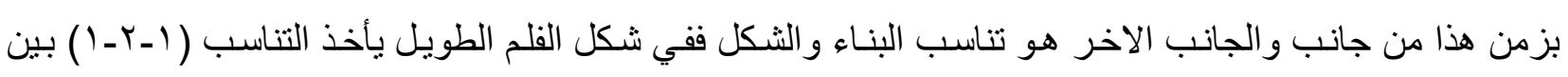

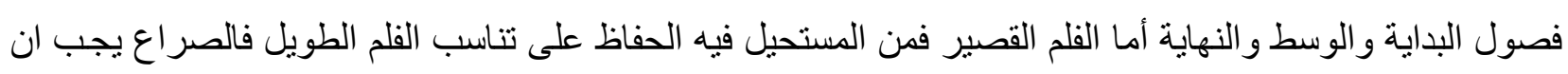
يأتي في الفلم القصير على نحو اسرع في الربع الاول من بداية الفلم ولذلك عند تأسيس القصة في الفيلم القصبر يجب ان يأتي سريعا في البداية والوسط وان يترك الجزء الأكبر في محاولة الثخصية في أن تجد حلاً للمشكلة التي أمامها و وان يأتي الحل سريعاً، أيضا في الفيلم القصير يجب أن يكون الهدف أكثر إلحاحـاً من الفلم الطويل أن كلمـا في الفلم 
القصير يعتمد على عنصر الاختز ال و الضغط فلبس هنالك وقت كافي لاستكثاف العلاقات بطريقة متمهلة ملائمسة للفلم الطويل ،و أيضاء من مميز اته أن للفيلم القصير نزعته الذاتية و الابتعاد عن الو اقعيـة ويعطي بسهولة للكاتب أو المخرج فرصة وضع صوته الخاص مباشرة في الفلم وغالبا تكون الثخصية الرئيسية و هدفها وعاء لأفكار الكاتب او المخرج كما وان للفلم القصبر مساحات جمالية وفنية واسعة في التطبيقات التجريبية للشكل و المضمون.

\section{التجريب في الفبلم القصير:}

عندما نتكلم عن الفيلم القصير جماليا وفنيا يجب أن نرجع الى أصول هذا الفن وبداياته لما يشكله هذا الفن من أهميـة في السينما عمومـا "إن بدايـة الفيلم القصير تعود الى التجارب الاولى للسينما على يد الأخوة لومير (لويس وأوجست ) و هما أول من قدم عرض سينمائي في العالم في باريس تحديداً يوم ه ديسمبر عام 190 (،حيث قدموا فيلماً قصيراً عبارة عن خروج العمّال من المصنع بعد انهائهم يوم عمل وكان الفيلم عبارة عن لقطة واحدة دون

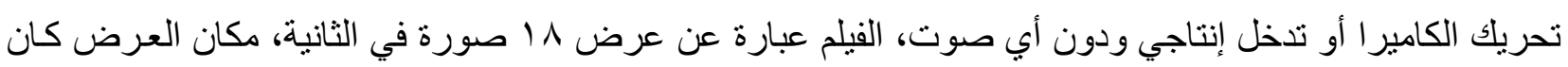
بداخل مقهى في باريس، حيث امتلأ المقهى بالمشاهدين وفضلا عن عنة ذلك "قدّم الأخوان الفيلم الاخر وكانت مدتـه جس ثانيـة فقط تحت عنوان(The Sprinkler Sprinkled) الفيلم عبارة عن بستاني يقوم بسقاية حديقة منزل، وبينما يقوم بعمله يقوم فتى بوضع رجله على أنبوب المياه فتنقطع المياه فيقوم البستاني بتوبيخ وضرب الفتى.وقد عرضا فيلم آخر في تلك الأمسية كان عبارة عن فيلم عائلي جميل، حيث يقوم الأب والأم بإطعام ولدهم وجبة الإفطار الصباحية

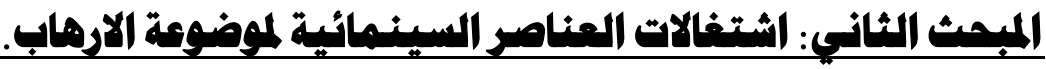

لا يخفى عن اي شخص ان السينما فن وأداة مهمة في الوقت الحاضر وهي من ادوات التعبير الفني ولها

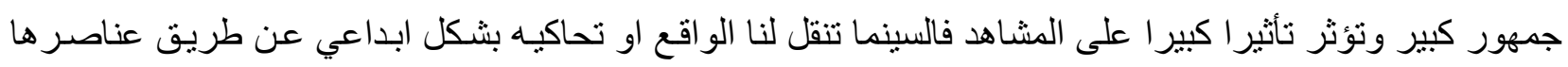
التي تنتغل بها، ان ما يميز اللغة السينمائية عن غير ها هي أنها من خلال تراصف اللقطات بشكل خطي يتولد ايهام

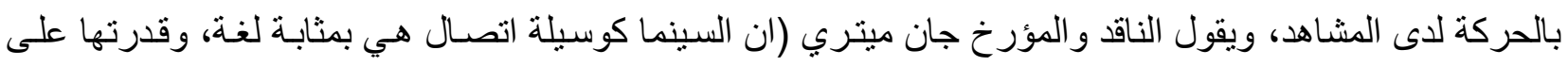

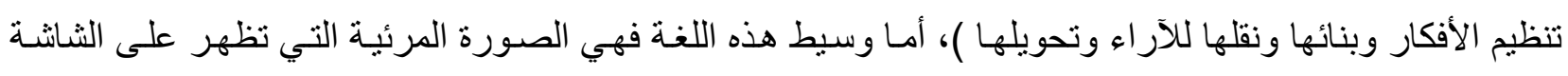
و هناك عناصر تميزت بها السينما ذكر ها مارسيل مارتن في كتابه اللغة السينمائية ومنها:

\section{مركة الكاميرا:}

تعتبر حركة الكاميرا واحدة من عناصر اللغة السينمائية المهمة ولها جماليتها الخاصة بها وقد ذكر "الكسندر

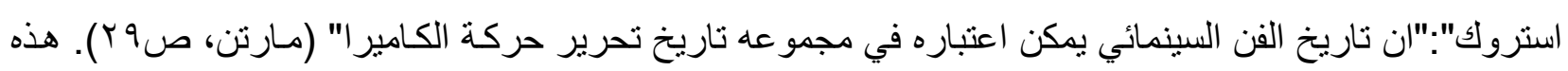

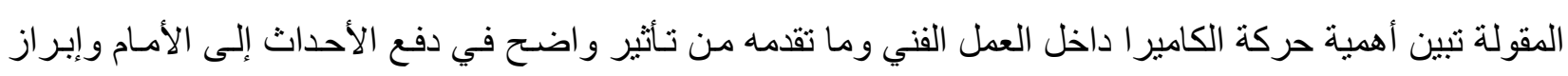
معاني كثيرة قد تكون غير و اضحة، ومن خـلال حركة الكامير ا تتضح للمشـاهد ولقد ذكر مارسيل مـارتن في كتابه

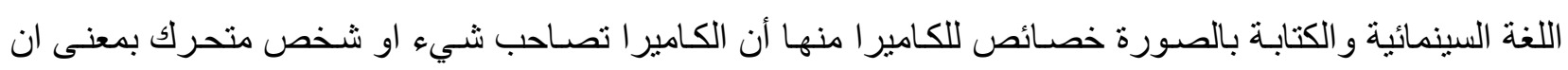
للكاميرا القدرة على متابعـة الثخصيات والأشياء التي تتحرك وإبراز أهمية الحدث الذي سيحدث في فيلم (الحشد والأربعين) وفي مشهد القتال مع داعش تتحرك الكامير ا مع مجموعة من الجنود باتجاه إحدى أوكار داعش، وذكر أيضـا أن حركة الكامير ا تعطي وهم الحركة لثـيء ثابت وذللك مـن خـلال تحريكها بصـورة معينه بمعنى ان نقوم 
بتحريك الكاميرا بشكل معين لتوحي للمشاهد بان هذا الثنيء الثابت قد تحرك من مكان هو قد تجسدت هذه النقطة في فلم (ارض مباركة للمخرج علي سـالم) في مشـهح البيت حيث تتحرك الكامير ا على احد شخصيات داعش الجالسـة تنتظر ساعة الصفر ثم فجاءة تتحرك الكامير ا باتجاهه لتوحي للمشاهد بأن هذه الثخصية قد تملكها الغضب وتحركت من مكانها رغم انها لم تتحرك نهائباً من مكانها ولكن بو اسطة حركة الكامير ا أوحي لنا بحركتها و أيضـا تقوم حركة الكاميرا بوصف المكـان الذي ستجري فيـه الاحداث مـن خـلال استعر اضـها للموجودات في المكـان في فلم نهايـة (الار هاب و التطرف للمخرج احمد ناصر ) مشـهـ الاستعداد لمقاتلة داعش تتحرك الكامير الترينـا الجنود و المعدات استعدادا لمحاربة داعش أيضا تقوم حركة الكامير ا بتحديد العلاقات المكانية بين عنصرين من عناصر الحدث في فلم (الحارس إخر اج سرمد نور) مشهح غرفة النوم تتحرك الكامير ا باتجاه السلاح المركون في احدى زوايا الغرفة ومن ثم تتحرك باتجاه الرجل الو اقف في البـاب هذه العلاقة التي خلقتها حركة الكامير ا تفهم المشـاهد ان السـلاح و الرجل الو اقف تربطهما علاقة الامن و ايضا من وظلائف حركة الكاميرا التركيز على شخصية معينـة أو شيء مقدر لله ان يلعب دورا هاما في بقية الحدث في فلم (العودة للمخرج اسعد راضي) مشهد المكتب تقترب الكامير ا من الحاسبة التي يظهر فيها اسماء للجنود الذين سيقوم الار هابي في قتلهم في نهاية الفلم ومن هنا يتبين لنا مدى اهمية حركة الكاميرا

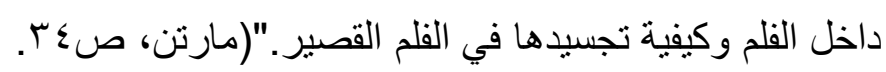

\section{المونتاة او التوليف:}

إن أصل كلمة المونتاج هي فرنسية وتعني الترتيب او التجميع تستخدم عـادة لوصف عملية تجميع وترتيب

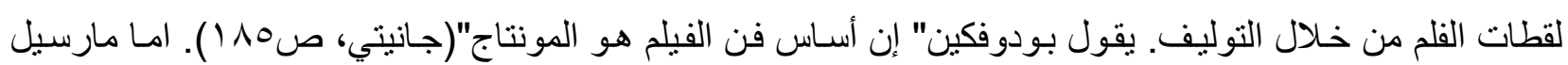

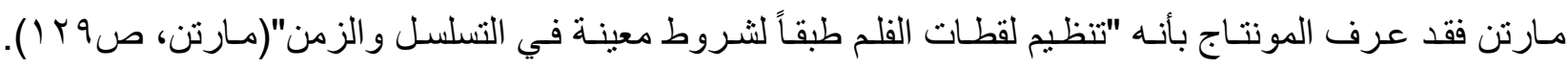
و هنالك تعريفات أخرى للمونتاج فهو فن اختيار وترتيب المشـاهد وطولها الزمني على الثشاثـة، بحيث تتحول إلى رسالة محددة المعنى ويستند (المونتير وهو الثخص الذي يقوم بالمونتاج) في عمله على خبرته وحسـه الفني وثقافتـه

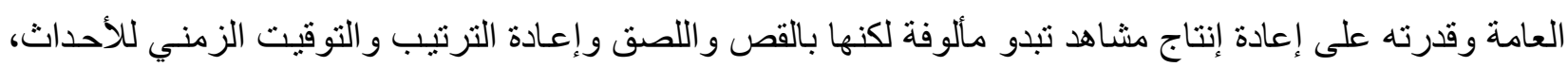

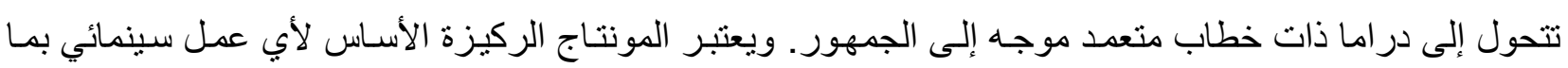

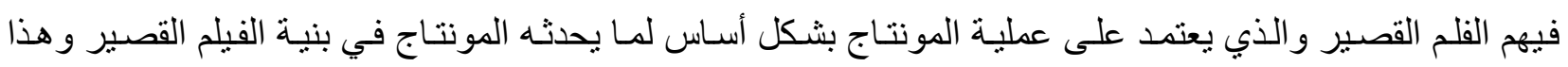
واضح في جميع الافلام القصيرة فعن طريق المونتاج يمكن رصف اللقطات التي صورت وتكوين المشـاهد ومن ثم

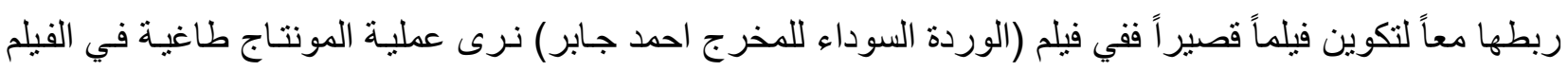

ككل فترنيب اللقطات و التداخل السردي في الفيلم ينم عن قيمة كبيرة لعملية المونتاج في هذا الفيلم.

|الأفاءة:

تعتبر الإضـاءة عنصر من عناصر اللغة السينمائية التي لاغنى عنها في العمل السينمائي، حيث تؤثر كثيراً

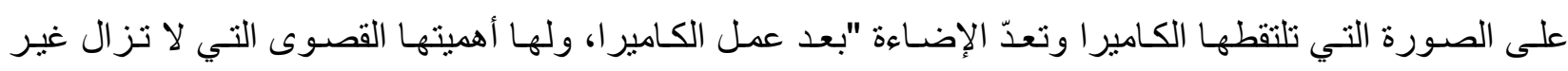

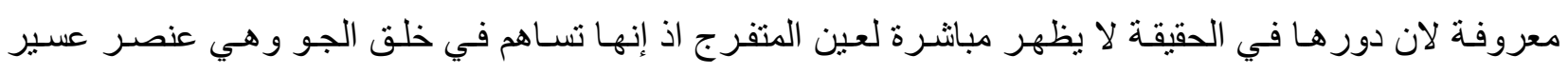

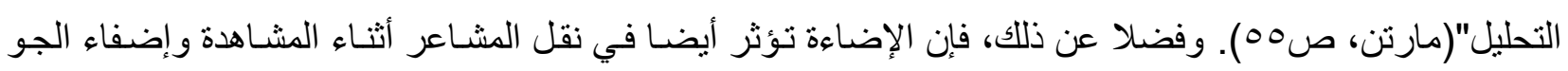


العـام، وتهتم الأفلام اهتمامـا كبير اً في الإضـاءة بسبب تأثير هـا السـري و الواضـح في الأفـلام، وهنـاك نوعـان مـن الإضاءة هما:

أـ- الإضاءة الطبيعية: و المقصود بها إضاءة الثمس والقمر .

بـ الإضـاءة الصـناعية: والمقصـود بها استعمال الأجهزة الكهربائيـة الخاصـة بالإضـاءة مثل المصـابيح على اختلاف انواعها.

ومن إحدى الطرق الرئيسة لتوظيف الإضـاءة في التصوير السينمائي تعزيز أو توضيح الحدث في المشـهـ ، و هنا يمكن استخدام الإضاءة لتوضيح أفعال أو أشياء معينة في المشهد، علاوة على إظهار عناصر أخرى من الحدث. وفي الفيلم القصير استخدمت الاضـاءة بشكل كبير لقدرتها على ابر از هدف معين او تسليط الضو ء على شخصية

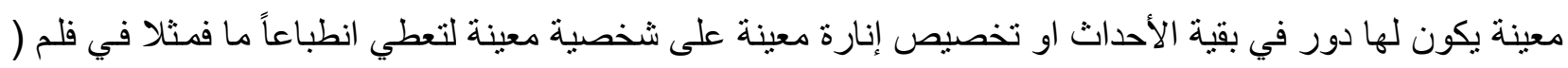
لست مجرماً للمخرج مهدي عبد الزهرة ) نرى كيف كان للإضاءة دور مهم في احداث الفيلم ففي مشهد حواري بين الثخصيتين الرئيستين نرى الإضاءة قد وجهت لهم من الأسفل و المكان فيه عتمة شديدة تبين للمشاهد مدى وحشيتهم وأيضا الظلام الذي يعيشون فيه يبين مدى تخلفهم الحضاري.

\section{الملابس والدبكمو:}

تلعب الملابس و الديكور ات دورا مهما في الفيلم لمـا لها من تأثثير و اضـح لدى المشـاهد فـالملابس هي أحد

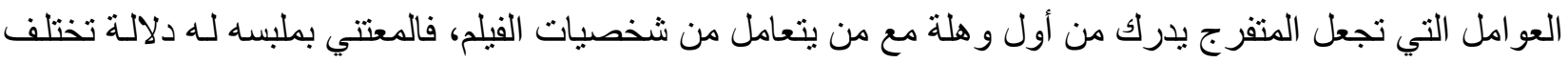

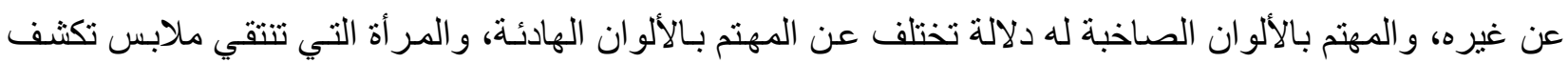
عن مفاتنها بخلاف المحتشمة، والتلميذ الذي أهمل زيه المدرسي بالتأكيد يختلف عن التلميذ المهتم بزيه المدرسي، هذا

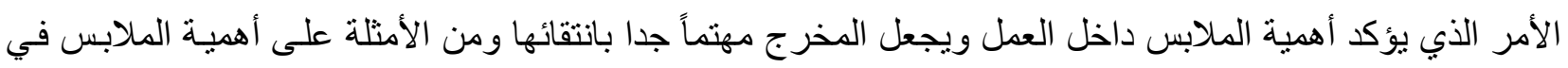
فلم (الحثد المقدس) نستطيع التمييز بين القوات الامنية من خلال ملابسهه و ايضـا نميز داعش و العناصر الإرهابيـة

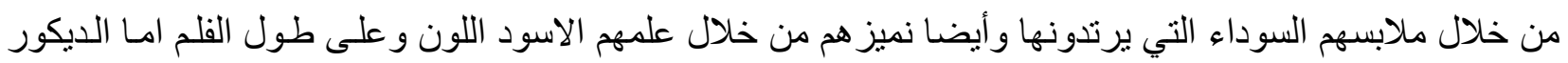
فهو ايضا مهم جدا في الفيلم وله اهمية لاتقل عن اهمية الملابس، ان اتجاه السينما يتطلب أن يكون الديكور دقيقاً في و اقعيته حتى يتم اثبات صحة الحدث ويجب ان يكون الديكور و اقعيا ومن ضمن الحدث بمعنى ان يكون منماشي و ولائم للأحداث ومسـاهم في الحدث وأيضـا على الديكور أن يكون مسـاهم في دفع الحدث ويستطيع الديكور ان يخبرنا"عن اذو اق الناس و عاداتهم وقد يكون يحمل الديكور رمزيـة معينـة خاصـة بالسينما ،كمـا يمكن للديكور ات ان تكون و اقعية او انطباعية معتمدة على طبيعة العمل الفني لدى المخرج"( السلمان ، صعء ). وقد لعب الديكور في الافلام القصيرة التي تتحدث عن الارهاب دورا بارزا و هذا ما رأيناه في فيلم (دمية للمخرج اسعد نور الدين) في أحد المشاهد حيث تظهر لقطة لسكين موجودة على احد الطبلات في الغرفة، ومن ثم تنسحب الكاميرا نشـاهد داخل الغرفة بساط قديم و أيضا ملابس سود معلقة على الحائط وقطعة سلاح في احد زو ايا الغرفة وفي جانب آخر من الغرفة يوجد علم داعش تتسحب الكاميرا إلى الخارج عبر الباب لنرى هذا البيت القديم وسط مزرعة، هذه الحركة أوحت للمشـاهد بان هذا البيت لأحد جنود داعش الذي تم تجنيده ، و هنالك العديد من الأمثلة من هذا القبيل ومستخدمة في الافلام القصبرة وهذا يؤكد على اهمية الديكور في العمل الفني عموما وفي الافلام القصيرة خصوصـاً. 
هي فن التعبير العالمية التي نستطيع أن نسمعها في كل مفاصل الحيـاة اليوميـة فنحن نسمع الموسيقى في رنات الهاتف وفي التلفزيون وفي وسائل الاتصالات وفي العمل ولهذا فهي تعتبر لغة عالمية يشترك بها جميع الناس

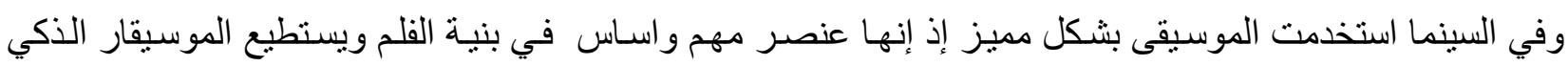

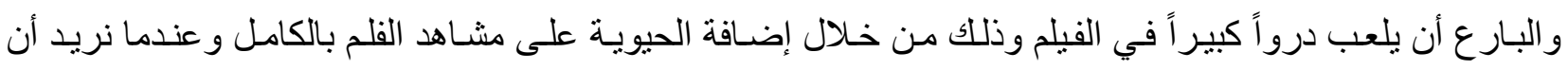
نعرف قيمة الموسيقى في الفلم ما علينا إلا أن نتفرج على أي فيلم سينمائي ولكن بدون موسيقى عندها نعرف أهمية الموسيقى فالموسيقى تبعث الحياة في الكثير من المشاهد و أيضا تستطيع الموسيقى تحريك مشـاعر وأحاسبس المشـاهد فهي تعزز الأثر السيكولوجي للفيلم، وعندما نتكلم عن الموسيقى فأنت تتكلم عن عالم كبير وعن معاني كبيرة تتتج عن الموسيقى، إن الغالبية العظمى من الأفلام لا تستغني عن الموسيقى لمـا لها من تأثنير واضـح وجلي يسـاعد في دفع القصة إلى الأمام وأيضا تسهم في إنتاج العديد من المعاني في الكثير من المشـاهد، يقول المؤلف الموسيقي (جيمس نيوتن هوارد) "هناك دور تلعبـه الموسيقى بمجرد أن تمتلـئ الثـاثـة، ليس بالضرورة أن تسمع كل التفاصيل، لكنها ستكون ور اء الحدث في السرد، من حوله، في الأمسام منـه، و على جانبيـ"(الياسري، صع). هذه المقولـة تبين أهميـة الموسيقى ودور ها في الفلم، ففي كثير من الاحيان نرى الموسيقى تفسر لنـا أفعال الثخصيات وأيضـاء تجعل المشـاهد مترقب دائما لما سيحدث فقي حالة الحب تظهر لنا الموسيقى الهادئة لتدعم المشهد بالرومانسية وفي حالة الحرب تقوم الموسيقى برفع معنويات الجيش من خلال الموسيقى الخاصة بالنشيد الوطني وغير هـا وأيضـا في حالة الخوف تدعم الموسيقى هذه المشاهد من خلال الترقب الذي تحدثه الموسيقى ، وللموسيقى أهميـة من حيث أنها في بعض الاحيـان

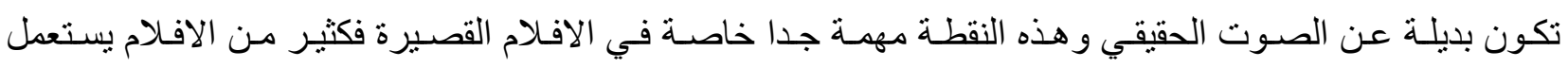
الموسيقى لكي يجسد فعل معين يحدث لا يسنطيع ان يقوم بتسجيله بالحقيقة ومثال على ذلك في فلم (مككن للمخرج حسين كاظم) نرى الموسيقى لعبت دور مهم في حالة الترقب لدى المشـاهد ففي مشهد انتظـار سـاعة الصفر لقطات للقاتل و هو ينظر الى ساعته مصحوب بموسيقى ترقب تجعل المشاهد في حالة من الترقب و أيضـا لقطات من خروج الطبيب و الفتاة والقاتل كلها متصـاحبة مع موسيقى ترقب تجعل من قصـة الفيلم مشوقة جدا، أيضـا استخدم المخرج الموسيقى بدلا عن دقات القلب عندما كان الدكتور يقوم بفحص القاتل.

في نهاية المبحث لابد أن اذكر بعض المهرجانات الي انعقدت في العراق والتي كان موضو عها الأسـاس هو

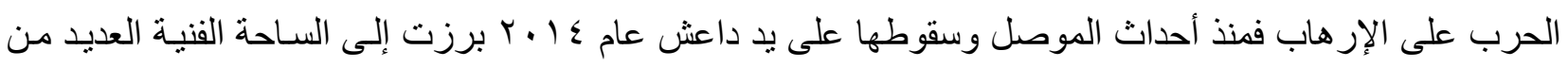

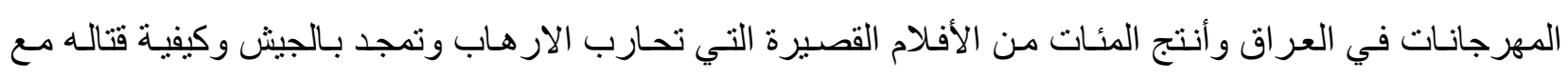

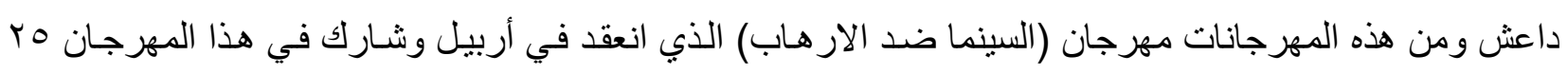
فيلما كلها تتحدث عن الار هاب وخطورته على الانسانية وطرق مكافحته ومن الافلام المشـاركة في هذا المهرجان فيلم (شروق) وفيلم (أنا سـامي للمخرج كي بهار) وفيلم (الرقم السري للمخرج بيتشو انبراد) وفيلم (ميلودي نايت

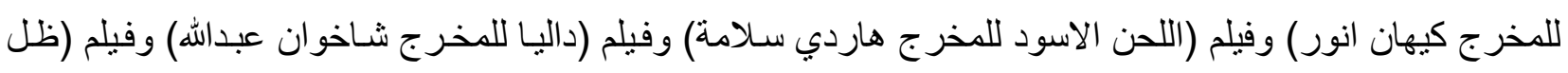
داعش للمخرج زانيار عدنان) وفيلم (بيشمركة للمخرج هردي حسن) وفيلم (علامـة استفهام للمخرج ادم اياد) وفيلم (كنيسة النجاة دموع لا تتوقف للمخرج نوزاد بولص) و أفلام أخرى عرضت في هذئ هذا المهرجان الذي يعتبر أحد أهم 
المهرجانات في العراق الذي يحارب الإرهاب، وهناك مهرجان آخر انطلقت فعالياته في ميسان باسم (رسـائل الحشد)

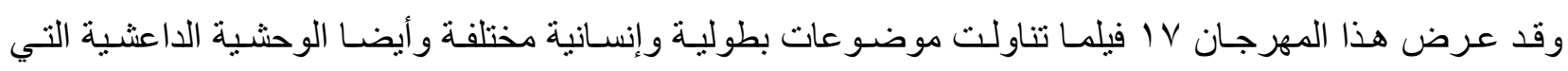
يمارسها داعش ضد المدنيين ومن هذه الافلام هي فيلم ( • . اللمخرج سرمد الأسدي) وفيلم (الثـيد الطائر للمخرج سالم شدهان) وفيلم (أمل للمخرج حمح عبد الستار) وفيلم (حكايـة فلم للمخرج علي المختار) وفيلم (حلم للمخرج ليث القريثي) وفيلم (حماة للمخرج صباح نجم) وفيلم (ربمـا للمخرج عقيل الموسوي) وفيلم (حرب أخرى للمخرج محم شوفي) وفيلم (سين كللمخرج احمد رعد) وفيلم (عشتار وداعش للمخرجة مي مصطفى) وفيلم (مطر اسود للمخرج عبد الاله الكر عاوي) وفيلم (مقاتل في إجازة للمخرج هدير جو اد) و غيرهـا من الأفلام وهنالك مهرجانـات أخرى في وهي

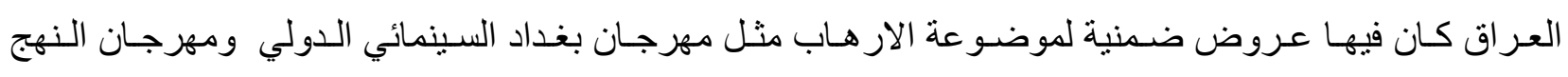

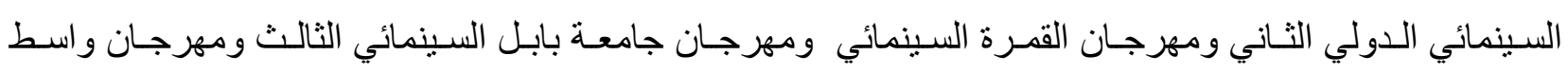
السينمائي الدولي ومهرجان السماوة السينمائي الرابع ومهرجان العراق السينمائي الدولي الاول ومهرجـان السليمانية

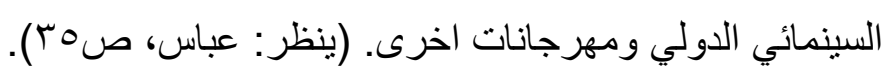

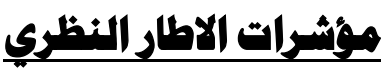

ا. توظيف عناصر الوسيط السينماتو غر افي لإبراز الملامح الأساسية للفيلم وفق معالجة يرتنئيها صانع العمل.

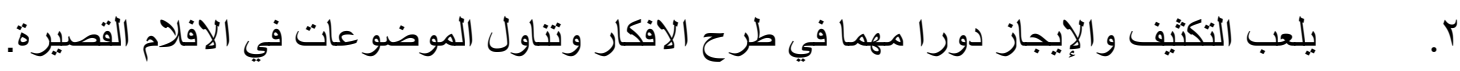

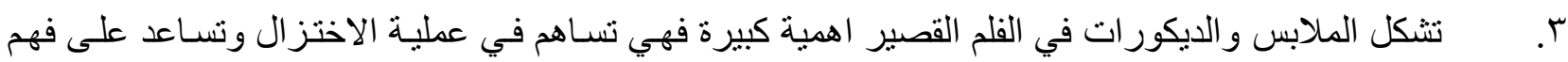
الشخصيات و الأحداث من الوهلة الأولى.

إجراsات البمث

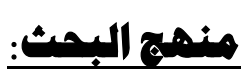

اعتمد الباحث في انجاز هذا البحث على المنهج الوصفي الذي يتضمن التحليل و الذي يعرف بأنه "وصف مـا هو كائن ويتضمن وصف الظاهرة الراهنة وتركيبها و عملياتها و الظروف السائدة وتسجيل ذلك وتحليله وتفسيره" أبو لوائ طالب، صع 9). لان هذا المنهج يتناسب وطبيعة البحث ولأجل الخروج بنتائج تخدم اهداف هذه الدراسة.

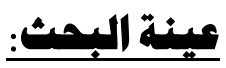
اختار الباحث أربع عينات فلمية بشكل قصدي لتكون اداة للتحليل في بحثه و هذه العينـات هي: ( ( الهروب، r. (عروس الثمس).

\section{اسلوب اختيار العينة:}

اختيرت العينة بصورة قصدية وذللك لما تحتويه من مو اضع تخدم البحث الذي نحن بصدده.

\section{أداة البمث:}

لتحقيق أكبر قدر ممكن من الموضوعية والعلمية لهذه الدراسة فإن الباحث اعتمد على مـا افرز من مؤشرات من خلال الإطار النظري كمعيار لتحليل العينة. 
تفترض عمليـة تحليل العينة استخدام وحدة ثابتـة ينبغي ان تكون و اضـحة لذا اعتمد الباحث على وصف المشهد زمن اللقطة داخل الفيلم كوسيلة محددة لغرض تحليلها واستخلاص النتائج منها لأغر اض البحث العلمي.

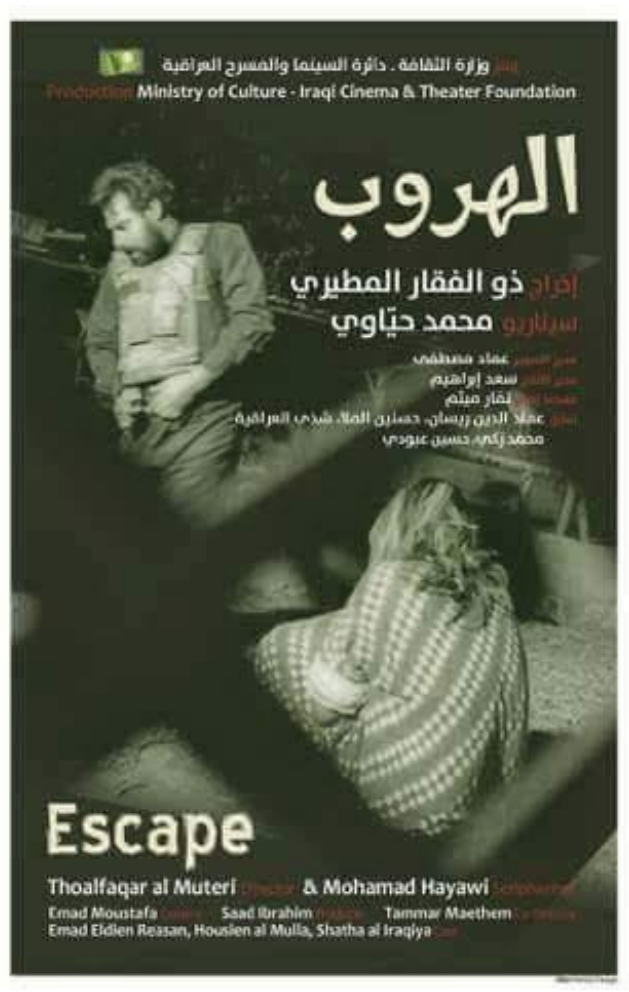

$$
\begin{aligned}
& \text { تمليل العينة } \\
& \text { فلم (الهروب ) } \\
& \text { سيناريو: محمد حياوي } \\
& \text { إنتاج: وزارة الثقافة } \\
& \text { دائرة السينما والمسرح } \\
& \text { مدير الإنتاج: سعد إبراهيم } \\
& \text { مدير التصوير: عماد مصطقى } \\
& \text { مونتاج وكراقك : منتصر العذاري } \\
& \text { المؤثرات الصوتية: علي فؤاد } \\
& \text { تمثيل: عماد الدين ريسان } \\
& \text { حسين الملا } \\
& \text { شذى العراقية } \\
& \text { محمه زكي } \\
& \text { حسين العبودي }
\end{aligned}
$$

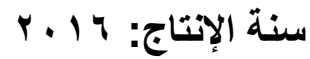

$$
\begin{aligned}
& \text { مدة العرض:؟ ؟ : ب دقيقة } \\
& \text { اخراج: ذو الفقار المطيري }
\end{aligned}
$$

القصة مستوحاة من أحداث حققية تدور أحداث الفلم حول شـاب نجى من حادثة سبايكر وبقي مطارد في

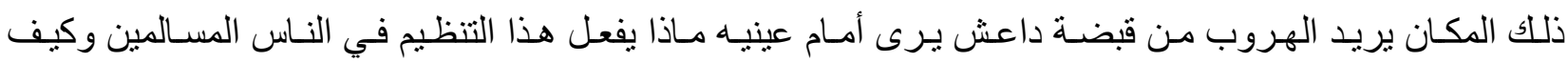
يغتصبون الفتيات ويقتلون الناس ، يو اصل طريقه حتى ينجو من التنظيم.

تمالي العينة

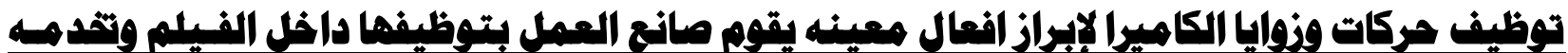
ب.

يهيمن على الفلم بصورة عامة استخدام المخرج لوجهة النظر الذاتية للكامير ا حيث ابتدأ بها الفيلم وانتهى بها

وذللك لتعميق الثعور لدى المنقرج للثخصية الرئيسة ودخوله في جو الفلم فنحن نشـاهد حركات وزو ايـا الكامير ا من اللحظة الاولى للفيلم وحتى اللحظة الاخيرة وهذه الحركات والزوايـا كان المخرج متعدد في وضعها لإعطاء جماليـة 


\section{يلعب التكثيف والإيجاز دورا مهما في طرح الانكار وتناول الموضوعات في الافلام القصيرة.}

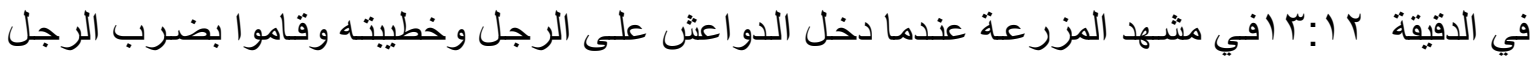
على رأسه ومن ثم التحقيق معه وبعدها جلبه للاعثي الذي يريد ان يغتصب الفتاة، وقام الداعثي بالطلب بالقوة من

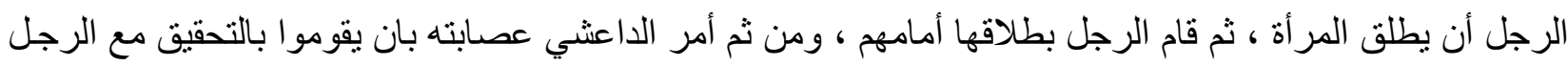

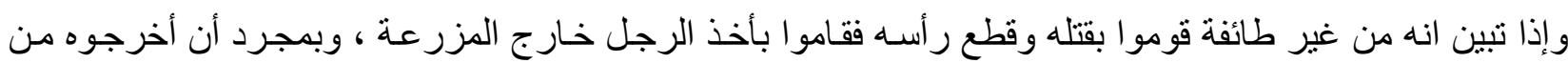
المزر عة يفهم المشاهد أنهم قاموا بقتله من غير ان يظهر المخرج على الثشاثـة فعل القتل ومن هذا المشهـد يتحقق المؤشر أعلاه.

في الدقيقة 9 ب:7 ا في مشهد خروج البطل من المزرعة و عندما تكلم مع الفتاة المغتصبة وطلب منها ان تدلـه على الطريق وقامت هي بوصف الطريق المـؤدي السى الهـروب بعدها يخـرج مـن المزرعـة وهـو يتـألم مـن اثر الرصاصة الموجودة في خاصـرته مع صسوته الذي يدل على وجعهه ومن ثم نسمع صدوت القطار القادم ثم تتحرك الكامير التبين لنا ان النهار قد حل ويقوم من مكانه ويتحرك باتجاه محطـة القطار من هذا المشـهـ يفهمنـا المخرج أنـه كان يجري طو ال الليل حتى وصل لهذا المكان من غير أن يرينا طريق الوصول الى القطار ومن هذا المشهـ يتحقق المؤشر أعلاه

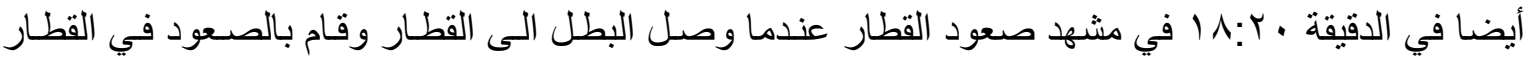
ومن ثم أغلق عينيه من خلال حركة الكاميرا ثم يفتح عينيـه فإذا هو في احد المستشفيات ويتلقى العلاج ، في هذا الشهـ اوصل لنا المخرج أن البطل قد وصل الى بر الامان وقد خرج من منطقة الخطر وقد وصل بالقطار الى احد

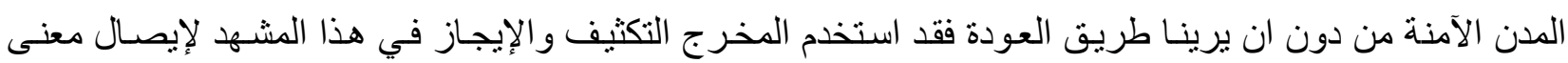
محدد وقد نجح فيه ، ومن هذا المشهد يتحقق المؤشر أعلاه.

\section{تشكل الملابس والدبكورات في الفبلم التصير أهمية كبيرة فهي تساهم في عمطبة الاغترال وتساعد على

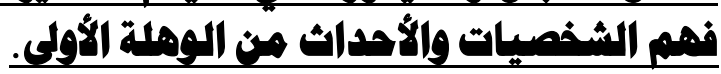

في الدقيقة الاولى مـن الفيلم وفي مشـهـ الاستهلال عندما تحركت الكامير ا مـن وجهة نظر الذاتيـة ليرى اصدقائه قد قتلوا فيقوم بالهرب نرى ملابس المقتولين المدنية دليل على ان الارهابيين لا يميزون بين الناس ويقتلون

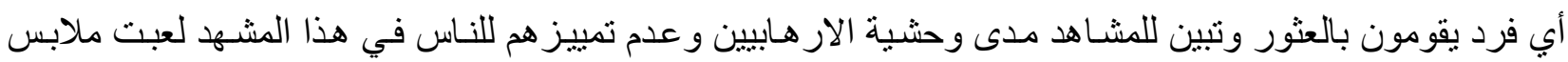
المقتولين دور ا كبير الأنها توصل معنى أن المقتولين ابرياء و الذي قام بقتلهم هم مجموعة من الارهـابيين ومن خـلال هذا المشهد يتحقق المؤشر أعلاه.

في الدقيقة §؟:ب في مشهد مطاردة البطل عندما قام البطل بالاختباء وراء احد العربات ويأتي مجموعة من

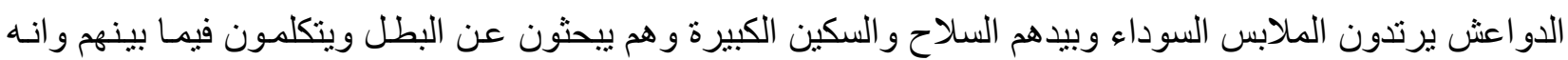
بمجرد العثور على البطل سوف يقومون بقتله وقطع رأسه ثم يمضون وهم ييحثون عنه من هذا المشهد يرينـا المخرج أن هنالك رجل مطارد و أن الذي يطارده هم عصدابات تتنمي إلى داعش التكفيري وقد أوصل المخرج لنـا هذا المعنى من خلال ملابس الدو اعش التي كانوا يرتدونها ومن هذا المشهـ يتبين اهميـة الملابس في العمل ومن هنـا يتحقق 


\section{توليل العينة}

اسم الفلم (عروسى الشسمس )

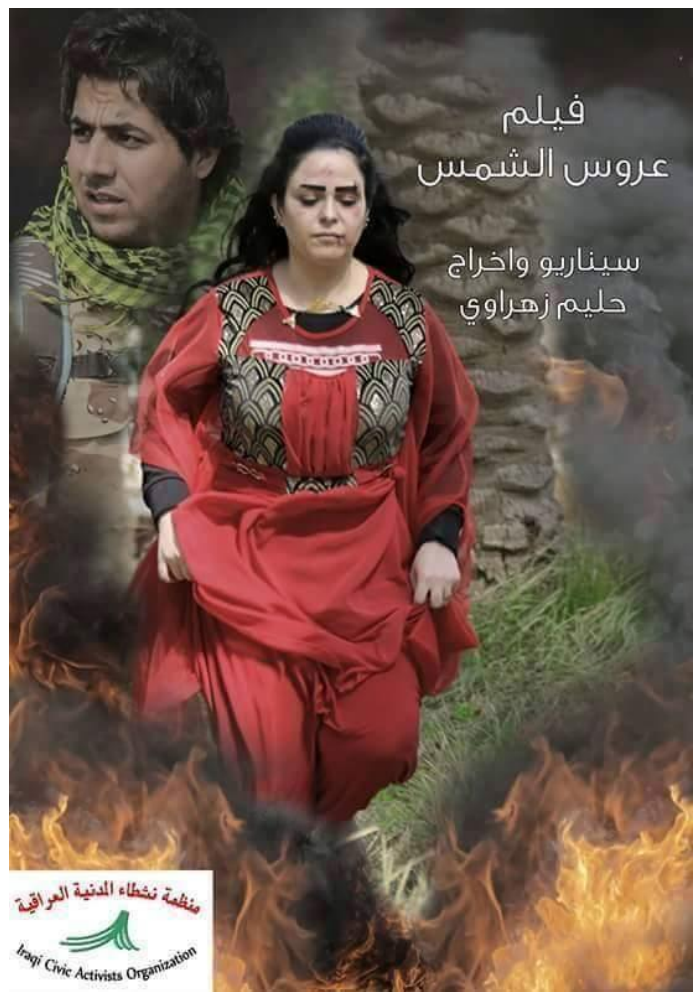

انتاج: منظمة ننطاء المدنية العراقية

تمثيل: مروة القيسي

عامر علي

بتول لطيف

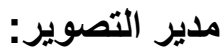

عمار عباس

مونتاج: حليم زهراوي

مساعد مخرج:(يمان علي

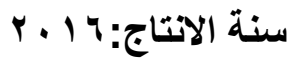

سيناريو وإخراج: ليم زهراوي

يتكلم الفيلم عن فتـاة أيزيديـة سـاقها القدر لتصبح بيد

عصـابات داعش فيقو مـون باغتصـابها، تهرب هذه الفتـاة مـن

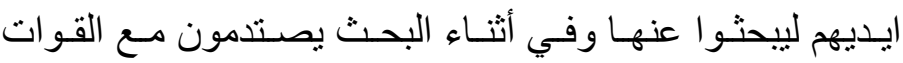

الأمنية لتنتلهم ومن بين عناصر القوات الامنية كان يتواجد حبييها الذي يعرف بالأمر ويبحث عنها ويجدها في أحد

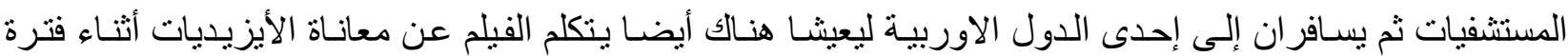
سقوط الموصل وكيف تعامل معهم التنظيم الارهابي من سبيهن وبيعهن و الاعتداء عليهن ومن ثم طريقة هروبهن.

\section{توظيف مركات وزواليا الكاميرا لإبراز أنعال معينه يقوم صانع العمل بتوظيفها داخل الفلم وتثدهه بشكل عام.}

في المشهد الاول الاستهلالي عند الدقيقة الاولى من الفيلم وبلقطة قريبة ومن حركة الكاميرا المتابعة لأقدام امر أة وهي تركض حافية ، وفي اللقطة الأخرى تظهر أقدام رجال وبلقطات متابعة ما بين المر أة والرجال، بعد ذلك الكابل تظهر لقطة عامة في بستان لمسلحين و هم يطاردون المر أة ، بعدها وبلقطة متوسطة خلفية متابعة لظهر امر أة ترتدي

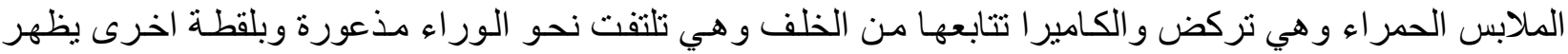

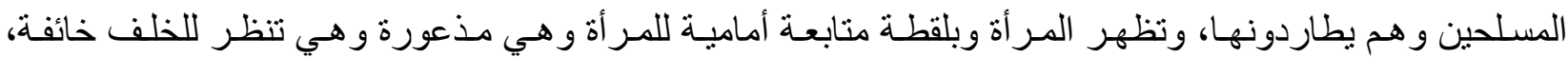
و المسلحين بلاحقونها، بعد ذلك تظهر بلقطة وهي تسقط على الارض و هي تزحف نحو الخلف،

وبلقطة من وجهة نظر المرأة والمسلحين يضربونها بالأسلحة على وجههاهومن لقطة اخرى يظهر منها أن الدطاردة و هية بسبب خوفها، لتسحح على وجهها وهي تظهر بلقطة قريبة ليظهر وجهها و عليه علامات الضرب، بعد ذلك وبلقطة عامة تظهر المر أة وهي تقوم، وبلقطة اخرى لتمسك بالنظلة لتتكئ عليها، في هذا المشهيد من الفليم قدم لنا المخرج و عبر لنا عن حالة الذعر و الخوف للمر أة التي تثتعر بالمطاردة من حركات الكاميرا المصاحبة لفعل 
المر أة من خـلال التنوع الحاصل مـا بين حجوم اللقطـات تـارة و بين زواياهـا للوصـول الى حالـة تعبيريـة من ذلك ألك استطاع المخرج أن يقدم لنا وصف لفعل تلك المر أة وبالتالي يتحقق المؤشر أعلاه.

\section{بلعب التكثيف والإيهاز دورا مهما في طرح الانكار وتناول الموضوعات في الافلام القصيرة.}

في مشهد لقاء البطل بحبييته في المستشفى في الدقيقة ـ ب: 0 عندما فتحت عينيها لتجد نفسها داخل المستشفى

وبجانبها حبييها هذه اللقطة فقط كانت كافية لتوحي للمشاهد انها دخلت المستشفى للعلاج وقد شفيت تماماً. في مشهر السفر في الدقيقة 9 :م عندما يقوم المخرج بتصوير لقطة لطائرة وهي تهبط في المطار مكتوب

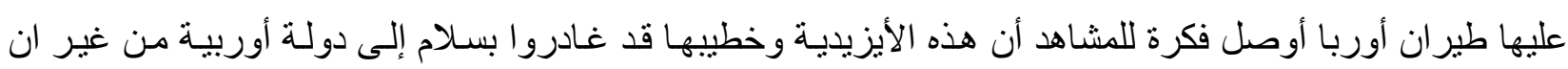
يظهر هما في المطار أو أثناء، السفر اكتفى المخرج بهذه اللقطة وقد كانت كافية لتوصيل المعنى للمشاهد.

في المشهد في الدقيقة به, r ويظهر الإرهابي الداعثي وبلقطة أوفر شولدر مع المر أة الأيزيدية وهو يحـاول إقناعها بارتداء الزي الخاص بها و هي ترفض، فيضربها على وجهها، وبلقطة أخرى كاملة للمر أة وهي تقع على ولى

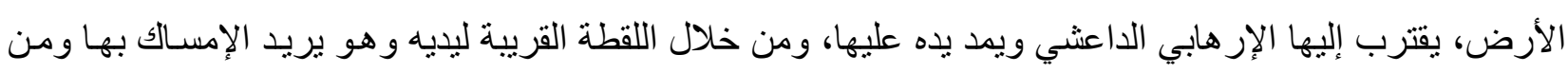
تغيير وضوح الصورة لينتقل إلى مشهر آخر، من هذا المشهد يتضح المؤشر أعلاه فمن الإيجاز باللقطة لم يظهر حالـة الاغتصاب وبالتالي وصلت الفكرة بأن الإرهابي قد اغتصب المر أة الأيزيدية.

في مشهد الاستهلال في الدقيقة الاولى عندما كانت تركض البطلة المنهزمة من قبضـة داعش كانت ملابسها توحي للمشاهد أنها من الطائفة الأيزيدية إذ إن هذه الملابس يرتديها الايزيديين في أوقات فرحهم واحتفالاتهم الخاصـة

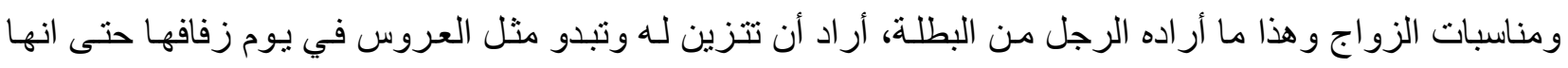
رفضت فقام بضربها و إجبار ها على لبس هذه الملابس ، أما الملابس السوداء التي كانت ترتديها العصابة فكانت تمثنل تتظيم داعش فبمجرد أن ينظر المشاهد إلى ملابسهم يعرف أنهم من تتظيم داعش. لهاه

\section{تشكل الملابس والديكورات في الفيلم الثصير أهمية كبيرة فهي تساهم في عمبية الاختزال وتساعد على

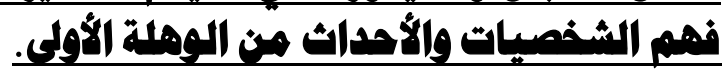

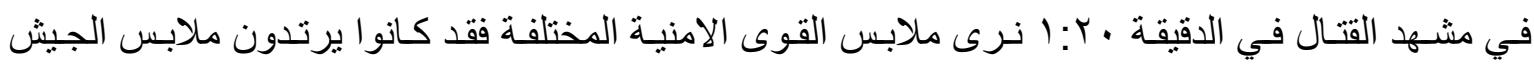

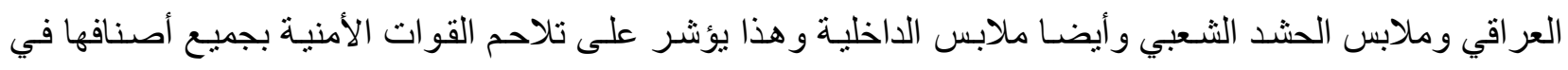

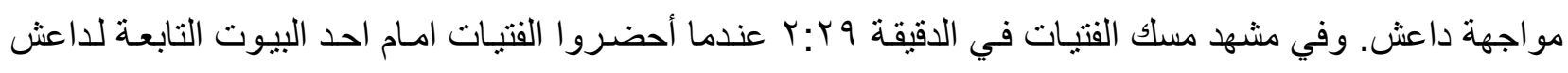
وقيام احد عناصر التنظيم بفلك قيود البطلة وإدخالها للبيت حتى يقوم باغتصسابها نرى الفتيات بملابس منزلية بسيطة

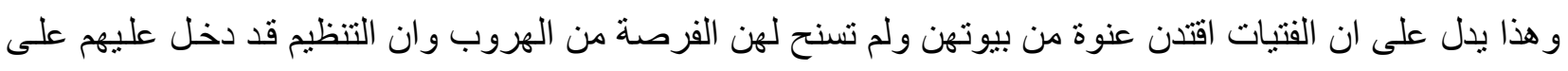
حين غرة. اما الديكور ففي مشهد اغتصاب البطلة في الدقيقة 0؟:؟ عندما دخل عليها الرجل الذي يريد ان يغتصبها

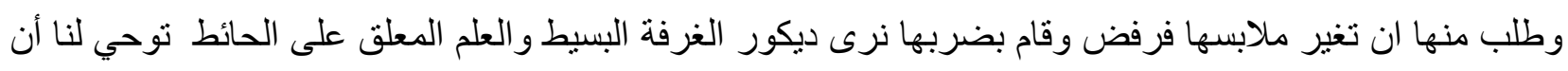
الدو اعش لا يأبهون لأي بيت ويستعملون بيوت الناس لأغر اضهم الدنيئة. ايضا في مشهد الزواج في الدقيقة بـ:1 عندما قام رجل الامن وحبيب البطلة بوضع خاتم الزو اج بيدهاو هم فرحين ، نـرى البطلة ترتدي ثوب اسـود اللون دلالـة على انها رغم فرحها بـالزو اج إلا أنها لاز الت تعـاني آثار 
اغتصـابها مـن قبـل داعش. مـن المشــاهد أعـلاه اتضـح المؤشـر فــن الملابس أعطى المخـرج رمزيـة للأشـخاص الموجودين بالفيلم فوضح الرجال الذين ينتمون لاعش وقدمهم من ملابسهم السوداء وكذللك رجال الحشد الثـعبي من

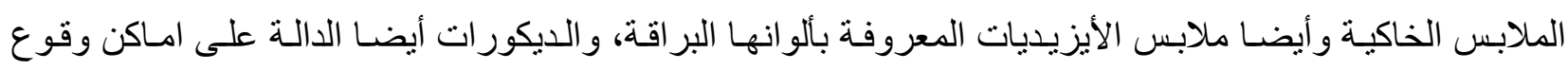
الاحداث مثل القرى و المستشفيات.

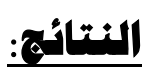
اعتمد الفلم القصير على الإيجاز والتكثيف في ابر از موضوعة الارهاب.

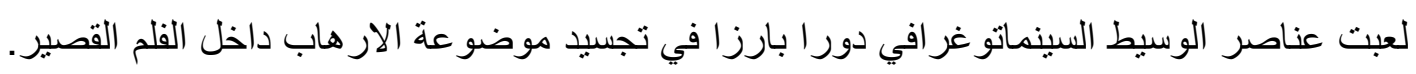
تعتمد الافلام القصبرة التي تناولت الارهاب على الثخصيات من حيث ايصال المعنى للمتلقي. يلعب المكان في الافلام القصيرة دوراً مميزًا إذ يقوم بتركيز انتباه المتلقي وخلق جو يركز على على التفاصيل الدقيقة ، والجزئيات البسيطة التي تقود إلى أفكار بعيدة .

|الاستنت:اجات:

للرمز و الاستعارة اثتغال مميز في تقديم حبكة سردية متكاملة للأفلام القصيرة.

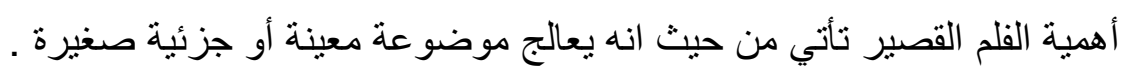
الأفلام القصيرة التي تناولت الارهاب نرى فيها انتغال عناصر اللغة السينمائية بشكل واضح.

\section{التوصيات:}

يوصي الباحث بدر اسة مستفيضة للكيفيات التي تعامل معها المخرجون في معالجة ظاهرة الار هاب. كما يوصي البحث بإجر اء در اسات حول الإرهاب وطرق معالجتها سينمائياً

|المقتزحات:

يقترح الباحث ان يكون هناك مركز متخصص لمعالجة ظاهرة الإرهاب سينمائياً قائمة المصادر:

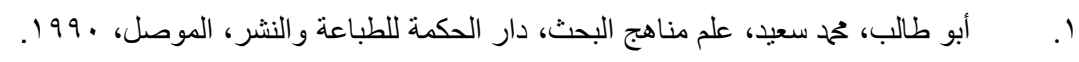

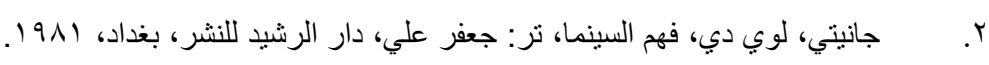

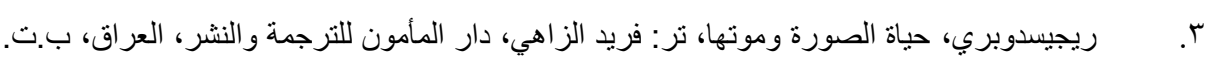

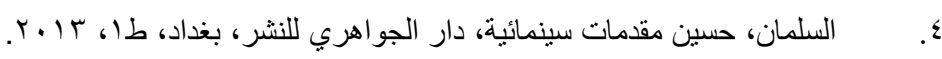

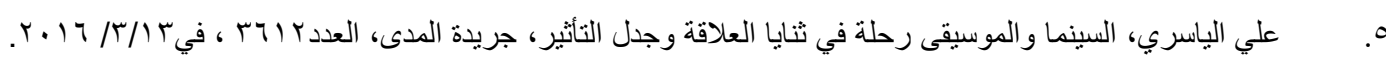

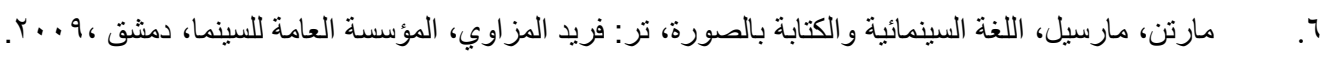

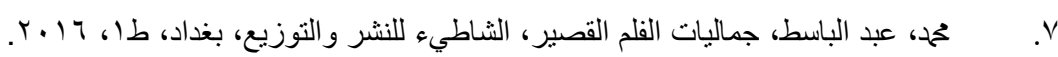

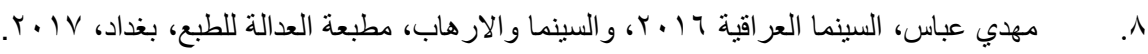

9 9. ياسين، عمر، الاشتغال الدرامي للتكثيف والايحاء في الفيلم الروائي القصير، رسالة ماجستير غير منشورة، جامعة بغداد، كلية الفنون
} 